\title{
Therapeutic Acupunctural Resonance: The Original Research
}

\author{
Adrián Ángel Inchauspe \\ School of Medical Sciences, National University of La Plata, Buenos Aires, Argentina \\ Email: adrian.inchauspe@yahoo.com.ar
}

Received 25 November 2015; accepted 28 December 2015; published 31 December 2015

Copyright (C) 2015 by author and Scientific Research Publishing Inc.

This work is licensed under the Creative Commons Attribution International License (CC BY). http://creativecommons.org/licenses/by/4.0/

(c) (i) Open Access

\section{Abstract}

The Chinese managed to interpret not only the natural rhythms of cosmic and seasonal cycles but the chrono-biological rhythms present in human body. What since long ago was merely taken to be a pre-scientific tradition has currently become a tangible reality. Nowadays, the specific frequencies pulsating along each meridian can be measured in hertz-according to its own resonance-as Acupuncture determined thousands of years ago. Their effort to establish a taxonomic classification of all environmental and human phenomena is closely related to Mathematics propositions of Euclid Five Regular Polyhedra, in order to consolidate the axiomatic-deductive model which we can now relate to the Chinese Theory of the Five Elements and their constant changes. As presented in OMICS Group Traditional Medicine-2015 Conference in Birmingham, it could be also proved that there also exists an inescapable relationship between Pythagoras and the Mathematical foundation of the Pentatonic Chinese Musical Scale. A simple way to incorporate the ideal frequency rhythm for each channel to correct its unbalanced situation is to insert said frequencies through the needles, by way of "antennae", restructuring the meridian's resonance affected and through it, of the Element it belongs to. Therapeutic Acupunctural Resonance therefore finds effective application when pins are used as "resonators", putting the frequency of said Element of the channel in line, so that they transmit by means of punctures pure vibratory patterns which shall recondition the Qi flow frequency which has been altered by the Chinese syndrome diagnosed to be treated.

\section{Keywords}

Five Elements, Euclid, Pythagoras, Therapeutic Acupunctural Resonance, Qi Recondition

\section{Introduction}

Back in early 1990s, Dr. Rupert Sheldrake’s book A New Science of Life: The Hypothersis of a Formative Cau- 
sation (1982) was edited in Spanish translation as Unanuevaciencia de la vida (Editorial Kairós-1990). Sheldrake, a member of the prestigious Royal Society-among whom theorists such as Cooke, Newton, Haley and Hawkins appear-stated his hypothesis on formative causation following the theory of morphic fields, defined as entities which organize and exert influence both on forms and behaviors of natural systems [1].

Based in turn on the Inter-Dependency theory, Sheldrake explains how-because of the co-evolution through collective information fields, i.e. morphic fields-every living being acquires its own organization form or pattern, nurtured by habits or thoughts that "in-form" the memory of species. Thus, morphic fields determine evolutional development and progress, DNA acting as "tuner" or "decoder" of that memory, providing its structures of the self-determination property [1].

It may well be the case that this theory contributes to interpreting the de-evolutional changes leading so many species to their extinction, according to the pulsating cyclical feature nature has. This enables the vital replacement of ecological niches by means of the generation of new species provided with higher adaptation capacities to their environment.

Unlike I-Ching, Sheldrake states in his works that there exists no such thing as an immutable law, but that there is a temporal reflection of habits which may be modified. In this way, morphogenetical structures conceptually evoke ancient Oriental wisdom to provide foundations to its millennial principles very much like the sacred Geometry established by Euclid as mathematical support for his own age [1] [2].

The Chinese managed to interpret not only the natural rhythms of cosmic and seasonal cycles but also the chrono-biological rhythms present in the human body [3], as we can see in Figure 1 [2]. What not that long ago was merely taken to be an empirical rendering of a pre-scientific tradition has currently become a tangible reality. Nowadays one can measure the frequency in hertz of each energetic level-according to its own resonancethat Acupuncture had thousands of years ago determined, besides those specific pulsating along each meridian [2] [4].

Their effort to establish a taxonomic classification of all cosmic, seasonal, environmental and human phenomena [3] is closely related to Euclid's proposition for Mathematics of a Fundamental Classification Theorem for his Five Regular Polyhedra in order to consolidate the axiomatic-deductive model par excellence which we can now relate to the Chinese Theory of the Five Elements and their constant changes [5].

\section{Antecedents for This Research}

In August 2014, I had the privilege of presenting a hypothesis whereby Chinese Traditional Medicine (TCM) ought to be considered an exact science by tracing a parallelism between the deductions offered by Euclid for his Five Regular Polyhedra and the Theory of the Five Elements proposed by CTM [2] [5].

Euclid (330-275BC.) was a virtuous and inspired mathematician whose transcendental contributions were
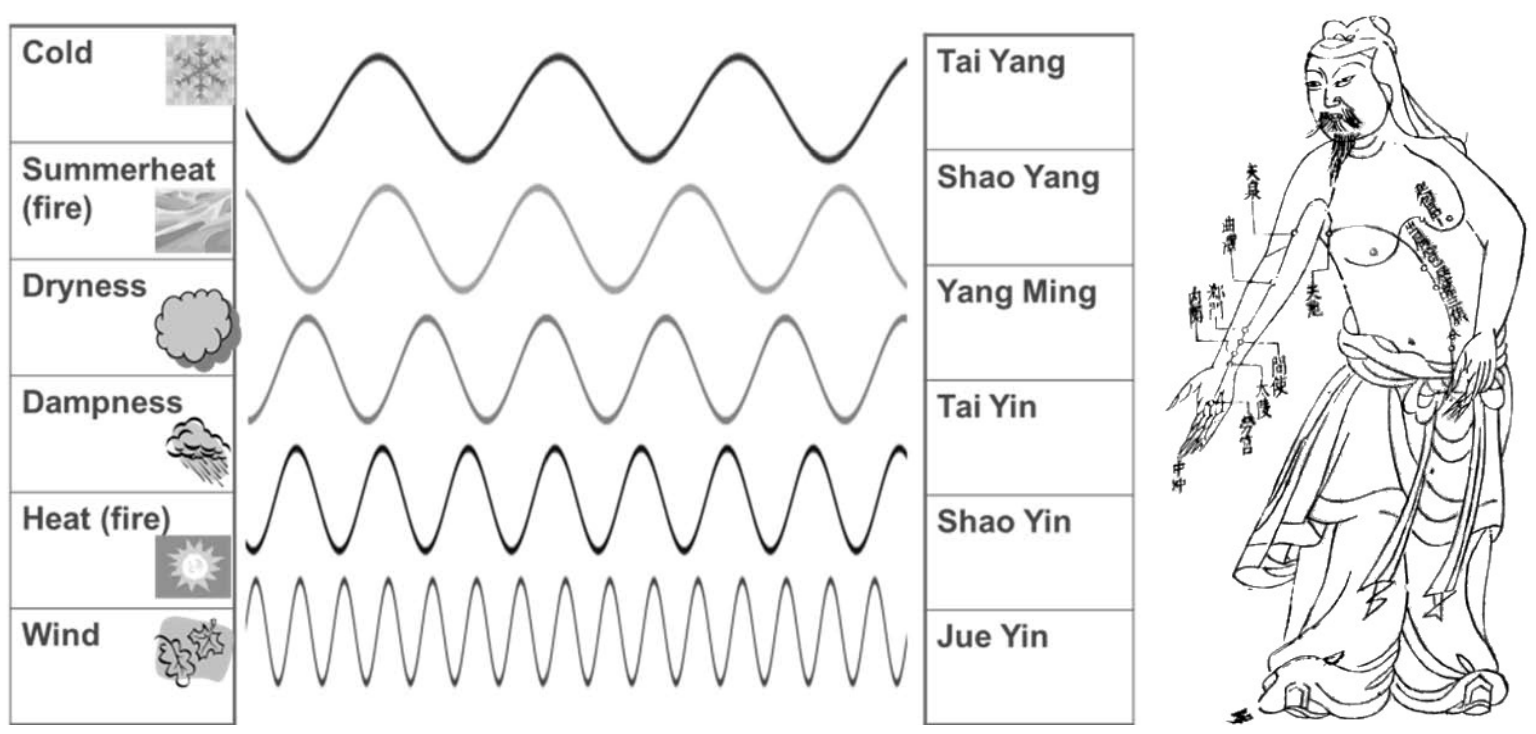

Figure 1. Vibrational frequencies along each energetic level [2]. 
not limited to the exact sciences (Figure 2) [2] but extended to human knowledge in general. The literary dissemination of his posthumous work, Elements has been compared-according to Prof. Pedro Miguel González de Urbaneja - to that of the Bible or Don Quixote and a perfect example of the axiomatic-deductive model of thinking [5] [6].

According to Proclus, Euclid—a disciple of Plato's Academy in Athens (Picture 1) [2]—was fascinated by the origin and formation of the five regular polyhedra, which he brilliantly presented in the propositions of his Book XIII, the last one of his formidable work [7].

By doing this, Euclid provided Mathematics with a perfect example of the Classification Theorem. Following Urbaneja's analysis, from Book VII to X Euclid analysed the geometry of the Platonic Solids; however, in Book XIII, he presented the last propositions for the Five Regular Polyhedra by taking to an optimum level Taetetus' previous line of thought as regards the Five Platonic Solids [8]. Euclid's brilliant work culminates in his last proposition (465, XIII, 18 [7]: “...to construct the Five Regular Polyhedra inscribing them in a same sphere and then compare the angles of the resulting figures" [2].

Thus, a sequential definition of those bodies started, beginning by the tetrahedron (XI, 12); the cube (XI, 25); the octahedron (XI, 26); the icosahedron (XI, 27) and the dodecahedron (XI, 28), finding the rates in the angles and then in succession the figures corresponding to each Solid (Table 1)—in Pérez de Urbaneja's words_- "with unique geometric genius" [8].

Thus the famous diagram was introduced showing step by step each of the preceeding propositions (Figure 3 and Figure 4) [7]. Once his Fundamental Theorem was established and demonstrated he was able to assert "Geometry has ruled that, even though there might exist an infinite number of polygonal shapes, the number of (possible) regular polyhedra is five, not one more, not one few" (Figure 5) [7] [8].

From that moment on, Euclid was devoted to obtaining the faces of such Five Dimensional Solids by determining their configuration in space.

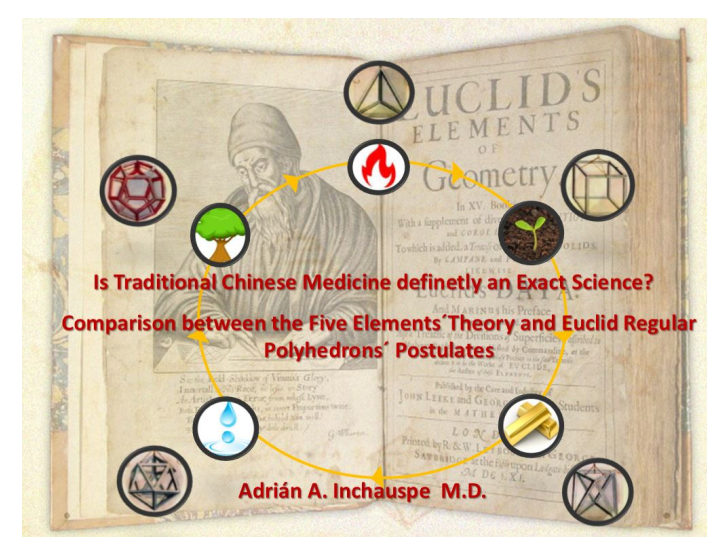

Figure 2. A caption of the August 2014 powerpoint presentation [2].
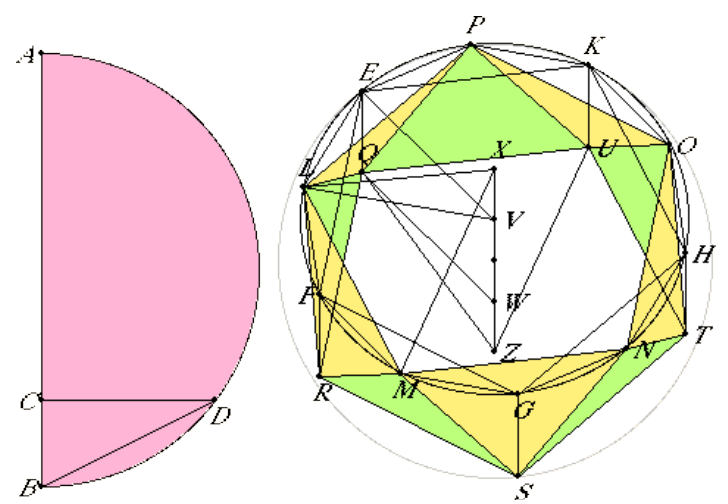

Figure 3. Euclid's elements. Book XIII—Preposition 16. 


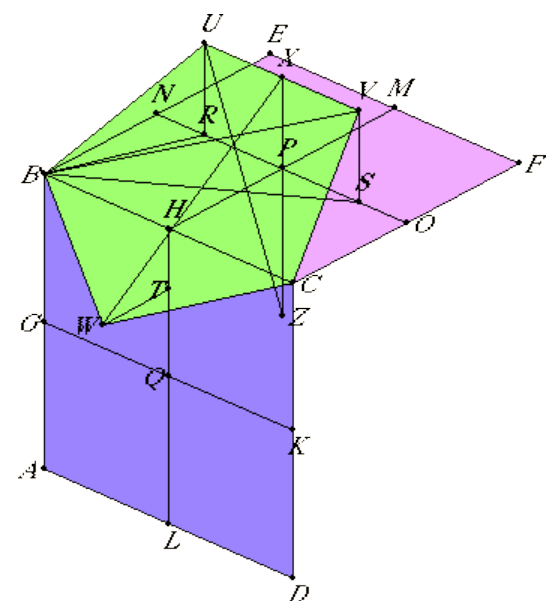

Figure 4. Euclid's elements. Book XIII-Preposition 17.

\section{Tetrahedron}

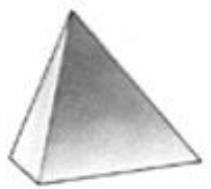

Cube

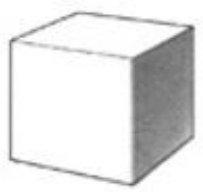

Octahedron

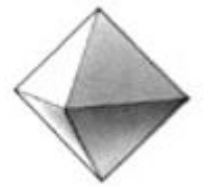

Dodecahedron

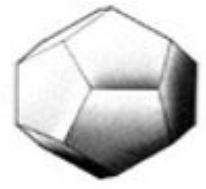

Icosahedron

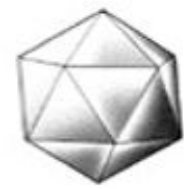

Figure 5. Source: The Five Regular Polyhedra. Euclid. Elements. Book I-IV: “General introduction: The constitution of the elements” 1. Gantry Axiomatic, pp. 48-65. [Translated title] Classic Gredos’s Library. Madrid, Spain, 2000. Spanish.

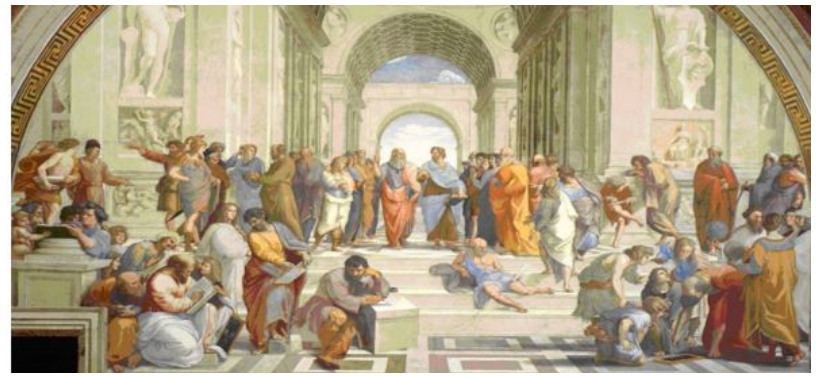

Picture 1. R. Sanzio’s The School of Athens [La scuola di Atene, 1510-1511] [2].

Table 1. Euclid’s elements. book XIII—Preposition 18th; pp. 355-56. Gredos Classical Library. Madrid, Spain, 2000 [7].

\begin{tabular}{ccc}
\hline Polyhedron & Proposition & Edge \\
\hline Tetrahedron & XIII. 13 & $\frac{2 R \sqrt{6}}{3}$ \\
Cube & XIII. 14 & $R \sqrt{2}$ \\
Octahedron & XIII 15 & $\frac{2 R \sqrt{3}}{3}$ \\
Icosahedron & XIII 16 & $\frac{R \sqrt{10}(5-\sqrt{5})}{5}$ \\
Dodecahedron & & $\frac{R(\sqrt{5}-\sqrt{3})}{3}$ \\
\hline
\end{tabular}


In a simple demonstration he then concluded that [9] "I am able to state that—other than the figures herein presented—no other figure with equilateral or equiangular angles can be constructed”.

W. Dunham's words seem suitable corollary to this part of the work, which I here transcribe: "Euclid has proved no logical argument can produce more than these wonderful images, leaving a mathematically irrefutable document that has lasted for 2300 years so far" [10].

\subsection{Euclid's Theoretical Background}

Which antecedents did Euclid use as basis for his geometric propositions? Which the stepping stones that enabled such marvelous conclusions?

We have previously mentioned that Euclid was a disciple of Plato's at the Academy in Athens and in the roots of his master's research he seemed to have found inspiration for his deductions [11].

Plato's Timaeus (Picture 2) is, in fact a work comparable to the Biblical Genesis, where another version of the creative Chaos is offered, analogous to the archaic Chinese vision on the origin of Creation. Plato wrote [11]:

Once his theory on the formation of Dimensional Solids was established, Plato stated a sequence in the order of Creation, thus giving origin to the Fundamental Classification Theorem [8] [11]:

The solid figure of the pyramid (tetrahedron) is element and germ of Fire; the second one in the order of creation (octahedron) represents Air, and the third one (icosahedron) is Water; Finally, a cubic form was given to Earth, for this element is the most difficult one to move about, the most tenacious one and its bases are the most solid ones [...] Therefore, we had to strive in order to compose those four types of bodies of extraordinary beauty and state that we have captured Nature (Figure 6) [11].

\subsection{Pythagoras' Theoretical Background}

"Everything is conformed by numbers" Pythagoras

As introduced in last OMICS Group Traditional Medicine-2015 Conference in Birmingham, UK, very much like the relationship existing among the Five Elements of Chinese Medicine and Euclid's Five Regular Polyhedra

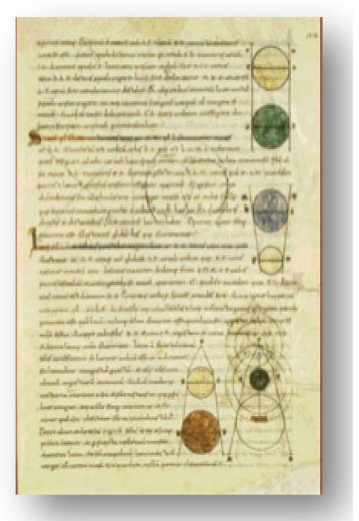

"Before the Creation, there were no measures or proportions. When God started to put order into the Universe, He first created Fire, Water, Earth and Air..."

"First, I believe-and this is beyond any possible doubt- that Fire, Earth, Air and Water are bodies..."

"However, every physical form is also provided with depth ..."; "And it is necessary that there is an area surrounding such depth".

"Each side (limited by itsarea) consists of triangles..."; "Each triangle is developed, each with its right angle and the others, acute ones".

Picture 2. Medieval manuscript of Calcidius’ Latin translation of Plato's Timaeus.
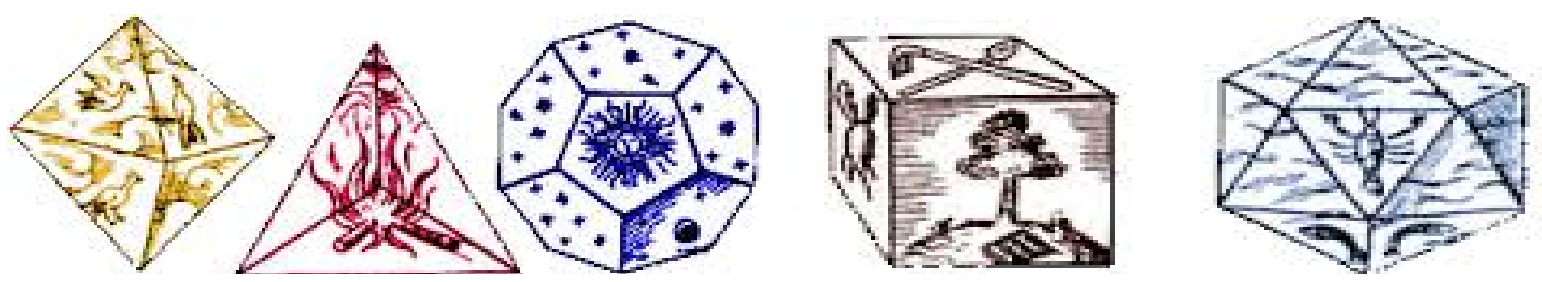

Figure 6. Euclid's elements. Source: Euclid. Elements. Book I-IV: "General introduction: The Constitution of the elements” 1. Gantry axiomatic pp. 48-65. [Translated title] Classic Gredos’s Library. Madrid, Spain, 2000. Spanish. 
could be proved, there also exists an inescapable relationship between Pythagoras and the Mathematical foundation of the Pentatonic Chinese Musical Scale [12].

Mathematics derives from the Greek mathema, which means knowledge. And it was Pythagoras himself who divided into four sections the exact knowledge of his time, namely: Geometry-Arithmetic-Astronomy-MusicMathematics (Picture 3) [12]; this, besides the creation of the Multiplication Table, of the theorem bearing his name and the construction of the first regular pentagon, all Mathematical demonstrations through deductive reasoning.

By listening to the sound of a smith's hammer on the anvil, Pythagoras tried to conform and group the sounds he found nice to the ear as well as their combinations that is why he called them harmonious. According to Boethius' account, Pythagoras - who was obsessed with the problem of mathematically explaining the fixed intervals of a scale-when passing by a smith's, the musicality of the hammer striking on the anvil called his attention (Figure 7) [13].

After having long spent in observation, he eventually made an experiment with five hammers (Figure 7) [12]. The weight of four of them was in a proportion of 12, 9, 8 y 6; the fifth one, whose weight did not correspond numerically to the rest, was the one spoiling the perfection of ringing. It was withdrawn and he listened to the hammers again. The biggest of them, whose weight was twice that of the smallest one, was an octave lower. As the weight of hammers 9 and 8 corresponded to the arithmetic means and harmony respectively, from the 12 and 6 weights, Pythagoras though that those two would provide the fixed notes of the scale.

Thus, supported by his mathematical genius, Pythagoras managed to deduce the seven notes we know to date as well as its intervals (Figure 8). He provided arithmetical support to those concepts, establishing besides that "the properties and relationships in musical harmony are determined by numbers." [13].

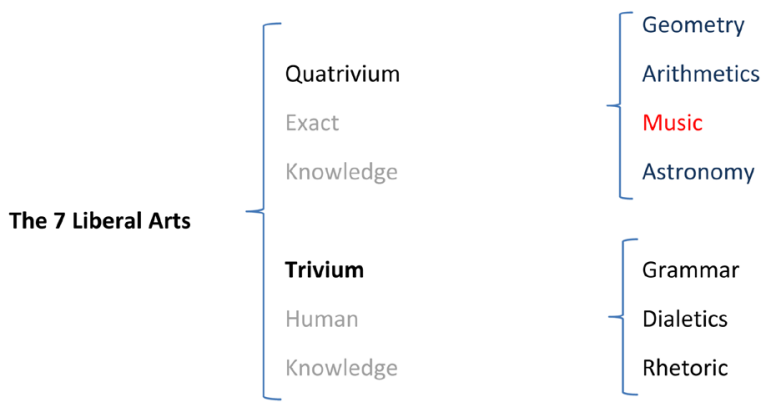

Picture 3. Seven liberal arts. Source:

http://latindecuisine.blogspot.com.ar/2010/01/las-artes-liberales-el-trivium-y-el.html [12].

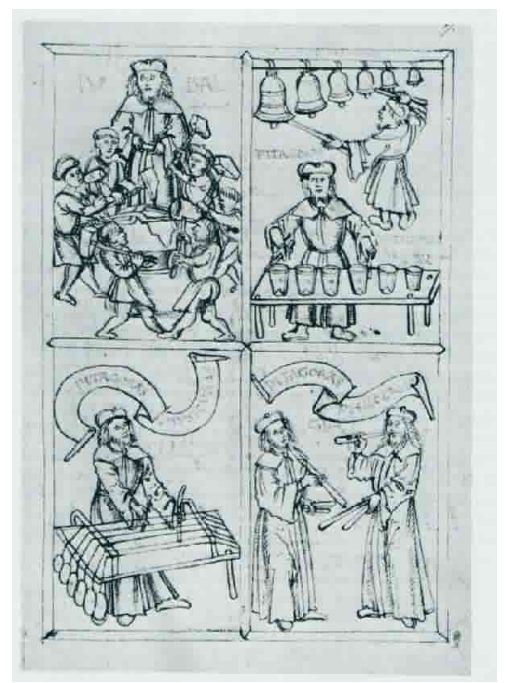

Figure 7. Pythagoras' experiment with the blacksmith five hammers. Source: http://sauce.pntic.mec.es/ rmarti9/WebBabilonia/Biografias/Pitagoras.htm [13]. 


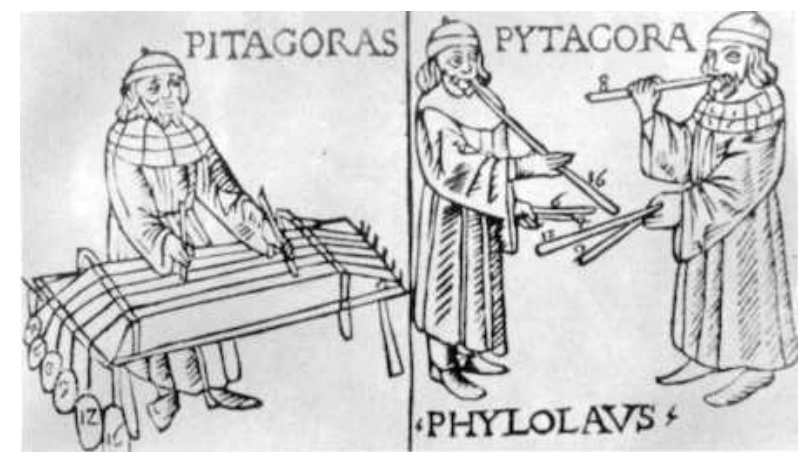

Figure 8. Pythagoras harmonics sound research. Source: http://sauce.pntic.mec.es/ rmarti9/WebBabilonia/Biografias/Pitagoras.htm [13].

Diatonic Scale: by using strings with lengths in 1:2; 2:3 (harmonic means) and 3:4 (arithmetic means) ratios, Pythagoras verified they vibrated according to relative combinations of such harmonious sounds. He also found out, in the musical proportion, that geometric means between two numbers equates the geometric means between its arithmetic and harmonious means [12]:

Thus, the notes we are familiar with, namely Do-Re-Mi-Fa-Sol-La-Si, emerged.

Pythagoric Scale: it is based on the following arithmetic sequence. As its geometric progression was immense, they used the Circle of Fifths (Figure 9) [13]. When they surpassed the octave, they multiplied by two the length of the string in order to go backwards to the original octave in a 9:8 rate, e.g.,

\section{Sol-Re-La-Mi-Si.}

Ethnomusicology classifies pentatonic scales into Hemionic or Anhemitonic ones. The former possess one or more semitones; the latter, does not.

In the Diatonic Scale, the biggest interval existing between notes is the ditone (not to be mistaken with scales solely formed by two tones) [12].

Major Pentatonic Scale: it can be formed by a scheme of intervals starting from a concrete note as, for example:

\section{Do-Re-Mi-Sol-La.}

Another way is by eliminating degrees VI and VII (withdrawing the sequence from Fa to Si), in which case, the scale remains Do-Re-Mi-Sol-La.

Yet another way of doing this is by following the circle of fifths, counting the "just fifths" as from one prefixed one and ordering the rest as a result, e.g.:

\section{Do-Sol-Re-La-Mi}

Minor Pentatonic Scale: it is a scale related to the Major Pentatonic Scale which starts by a not which is not Do [12].

In this brief way we have determined that Chinese music derives from a pentatonic-anhemitonic major scale. Its sequence, established by the passing of the Generative Cycle or Cheng is:

\section{Do-La-Mi-Re-Sol}

We can notice-as Euclid did to justify the exact scientific mathematical bases for the Five Elements in Chinese Medicine- that the selection of musical notes also has a precise and exact foundation in the development of Music, as Pythagoras explained.

\subsection{Retrospective Antedecents for This Research}

We shall now briefly refer to a revision of pulse therapy application at specific energetic vibratory frequencies:

\subsubsection{Electroacupuncture}

Yoshio Manaka was one of the pioneers in employing electric current on needles, trying in this way to "align" the hyper-electro conductive point along the meridian in question. This method, known as Ryodoraku Method 
was used as diagnosis though electro-acupuncture, as well as with therapeutic purposes, based on the frequency and intensity of the stimulus (Picture 4) [14]:

- Low frequency and high intensity: illnesses and chronic pain

- High frequency and low intensity: acute illnesses and pain.

Manaka also established his results in a group scale, according to efficiency:

A: very efficient; B: efficient: C: inconstant; D: symptomatic (Parkinson).

There also exists a painless pediatric system, with a few punctures at only $2 \mathrm{~mm}$ depth, derived from the previous one, called "Shonishin Method" [14].

\subsubsection{Acupunctural Lasertherapy}

This is a new, painless and efficient acupuncture technique with a wide range of indications.

The acronym LASER (Light Amplification by Stimulated Emission of Radiation) indicates the nature of the power from a narrow beam of monochromatic, coherent light provided by a device which offers such electromagnetic radiation (Picture 5) [15].

Low-power semiconducting lasers $(<2 \mathrm{Mw})$ with a Gallium arsenide diode are inexpensive, efficient and small; they allow for the modulation of the emitted radiation and are used with analgesic-anti-inflammatory purposes in Acupuncture.

Other indications for lasertherapy are stress, anxiety, tobacco addiction, food disorders and other types of addiction [15].

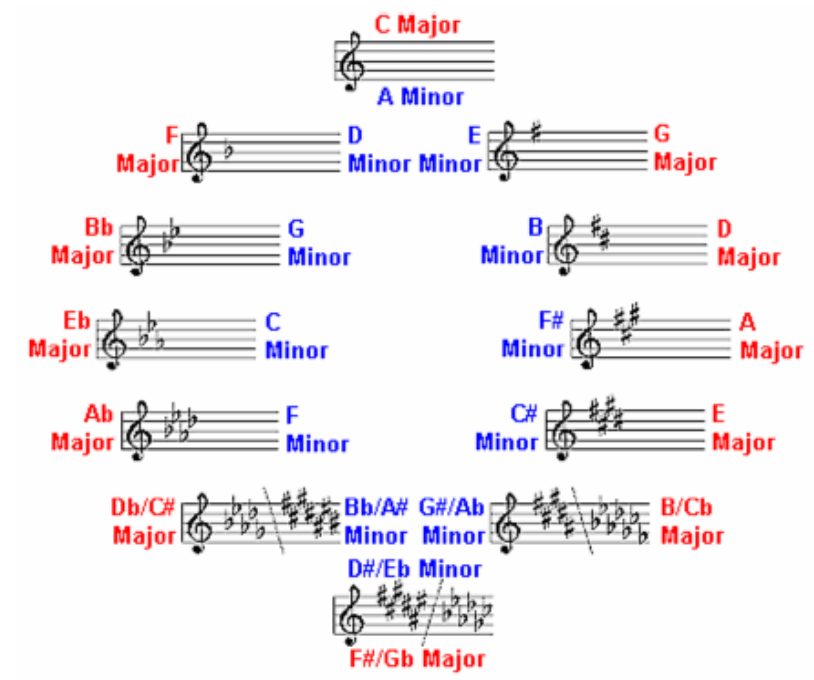

Figure 9. Cycle of fifths. Source: http://sauce.pntic.mec.es/ rmarti9/WebBabilonia/Biografias/Pitagoras.htm) [13].

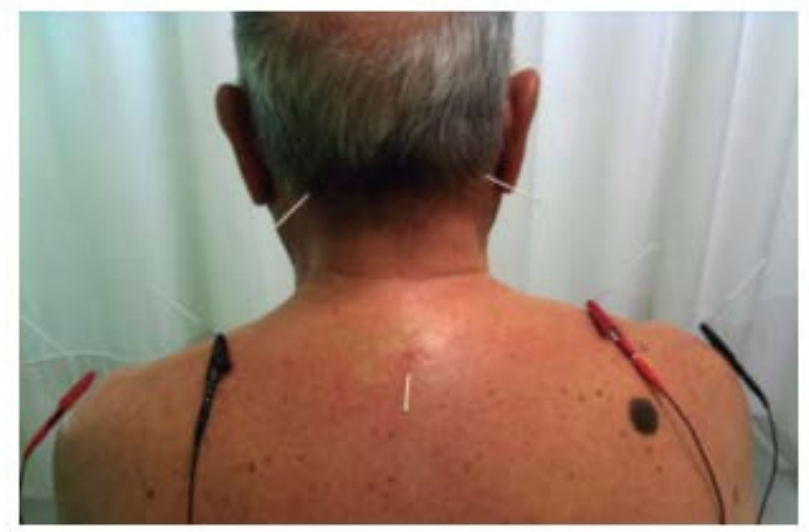

Picture 4. Electroacupuncture [14]. 


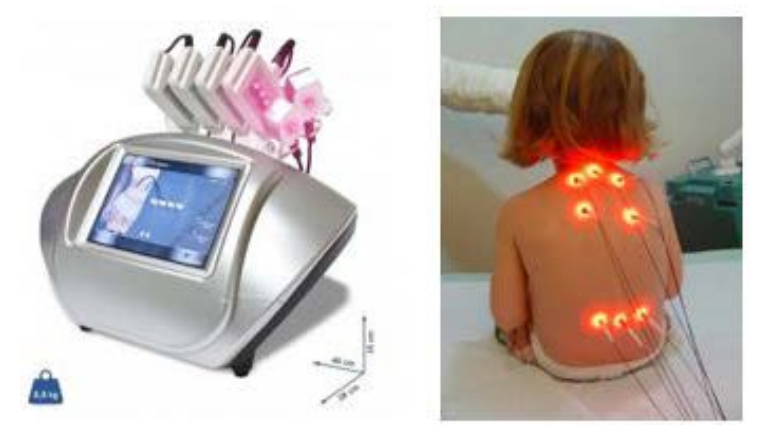

Picture 5. "Laserterapia: Tratamientos innovadores y dolencias”. www.lasersalud.es [15].

Sound therapies were already present before considering the theory of Therapeutic Acupunctural Resonance. Anyway, let us review some of the contemporary therapies related to this concept.

1) Five ElementFusion

Taoist Spiritual Alchemy also refers to the Five Element Fusion, resorting to a sub-vocalic intonation of specific Healing Sounds for each of the affected organs-following specific positions to be adopted during the session-for each of them [16]:

2) Tama-Do

As regards this, one can read in Webster's New Encyclopaedic Dictionary (1993): Human blood cells can respond to certain sound frequencies, changing form and color. It seems that modified or sick blood cells can heal and be harmonized by sounds.Fabien Maman (French musicianand acupunctor) (Picture 6) [17].

Maman uses non-invasive techniques by means of tuning forks on the Command or "Shu" Acupuncture point, accepting that vibration-along the meridian-transmitsits resonance to cell DNA, which in turn resends the message to the meridian's "counterpart" (the energetic field) thus modifying or erasing negative patterns that had an impact on the structures of the physical body.

Tuning forks are tuned to the chromatic scale $\mathrm{A}=220 \mathrm{~Hz}$-bearing in mind pianos are tuned at $\mathrm{A}=440 \mathrm{~Hz}$-in order to get a deeper resonance and a more prolongued vibration.

French physicist Joel Stemheimer corroborated the tone for each meridian, for he himself was the one to discover the sound frequency of elementary particles ("The Music of Molecules"). The tone of the tuning fork has to be in perfect concordance with the note of the organ to be treated [17].

3) TopologySystem

At the Manaka Institute in Japan there is an efficient treatment through micro-stimulations which regulate Acupuncture meridians. Such superficial neuro-stimulation (Neas Topology System) implies a bio-electrical interface which applies an "x" signal system to the human body (Picture 7) [18].

Meridians are accessed via the Shu points at wrists and ankles, which generate an electrical field in the whole body. Then, electrical micropotentials are applied, which modify channel conductivity. Their efficiency was proved in cases of blood hypertension; muscle-skeletal conditions; somnolence; anxiety; anguish; pain therapy. A marked improvement of neuronal activity was noticed at the frontal and left brain (concentration-memory) [18].

As to the current therapies with sonic radiations that are accepted and applied in the Western world, we shall make a brief reference to the fundamentals of ultrasound and radiofrequency.

\subsubsection{Ultrasound and Radiofrequency}

We mention here these allopathic therapies which use radiation with sound or electromagnetic waves; these are closely related to the use of vibrations at specific established frequencies. Below, their main characteristics:

1) Ultrasound

The discovery of the piezoelectric effect in France at the end of $19^{\text {th }}$ century by P. and J. Curie made the generation of waves viable thanks to the first ultrasound generator, built by P. Langenin and C. Chilowsky at the beginning of the $20^{\text {th }}$ century. Crystals such as quartz $\left(\mathrm{Si} \mathrm{O}_{2}\right)$ or barium titanate $\left(\mathrm{Ba} \mathrm{Ti} \mathrm{O}_{3}\right)$ are electrically polarized when compression is applied; that is, when an oscillating electric field is applied, they experience mechanical vibrations (Picture 8) [19] 


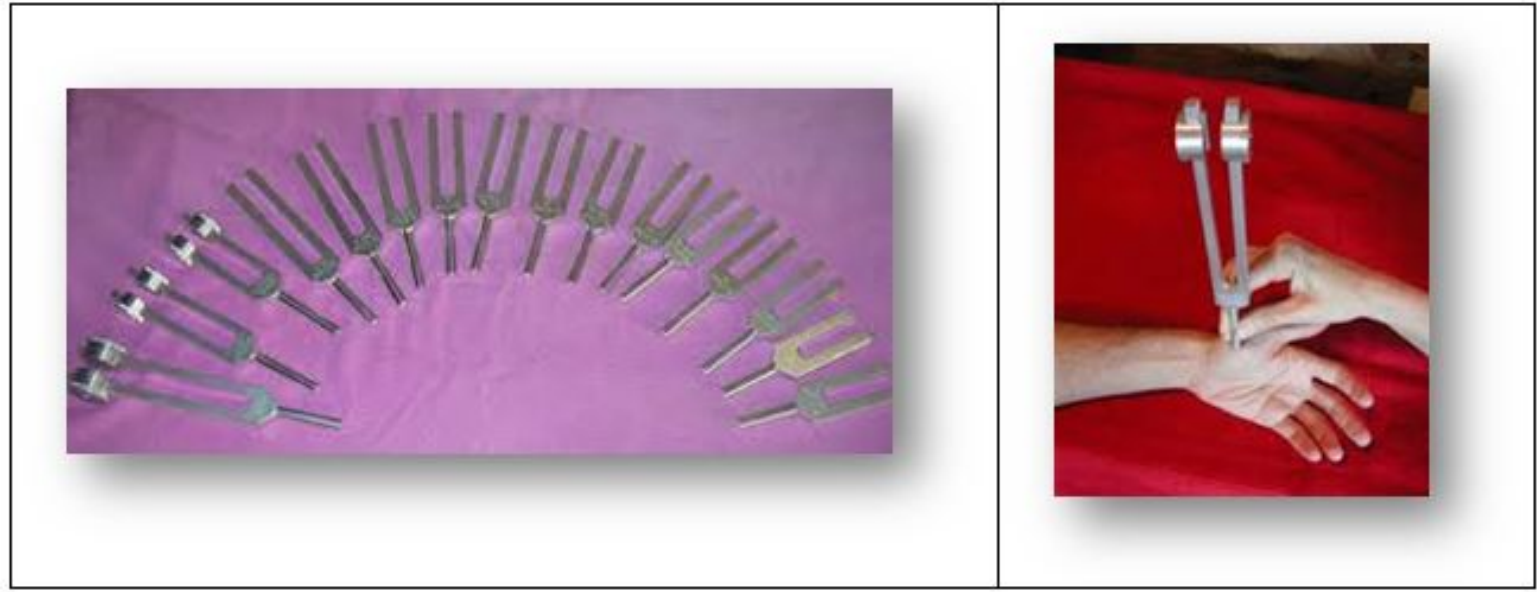

Picture 6. Mamman’s tuning forks. Source: http://tama-do.com/product/tuningforks.html [17].

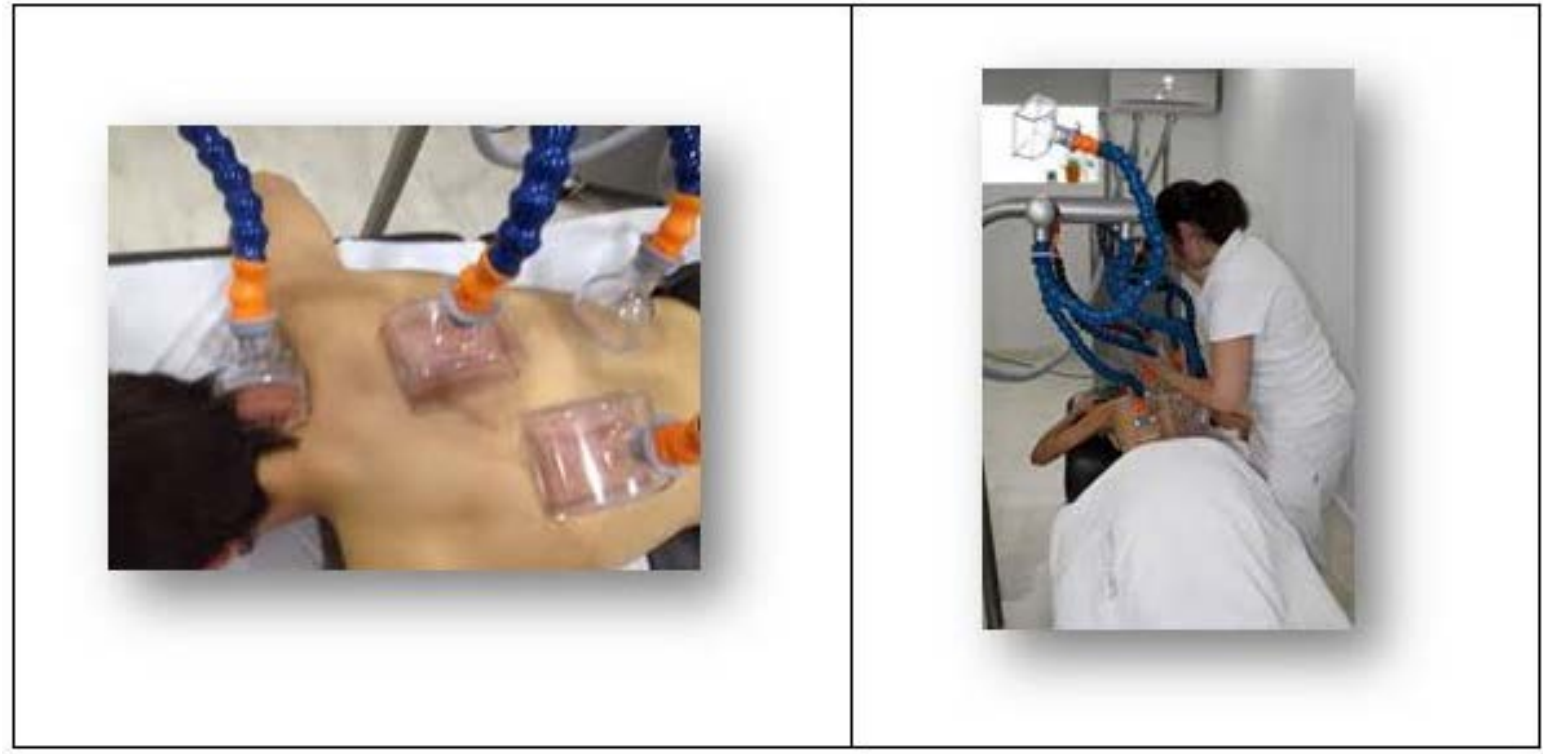

Picture 7. Topology system. Source: http://trade.nosis.com/es/www.acupunturaorekavitoria.com/1311065/s [18].

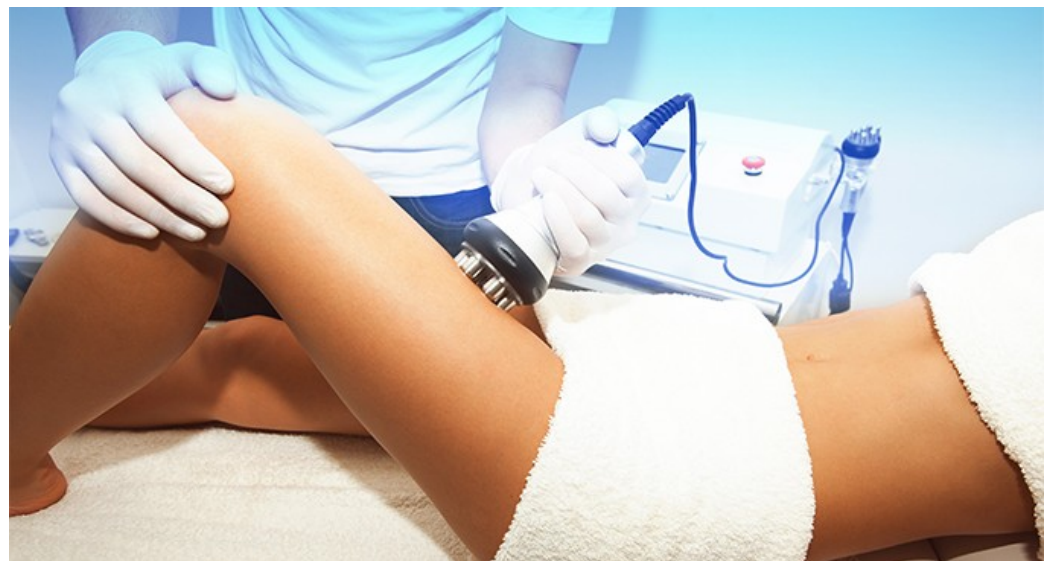

Picture 8. Therapeutic ultrasonography. Link:

http://www.astook.com/ultrasonido-para-adelgazar-o-cavitacion-ultrasonica-pros-y-contras/ [19]. 
If they coincide with the frequency of the vibration which is that of the tissue or organ to be treated, their width increases as a result of their resonance.

It is extensively used in Physiotherapy and Rehabilitation, for it generates beneficial metabolic changes at the level of the injury, generating heat due to the effect of ultrasound waves.

2) Radiofrequency

It consists of electromagnetic radiations simultaneously oscillating in the electric and magnetic fields; thus, an electric field is generated that changes from positive $(+)$ to negative $(-)$, causing a molecular rotational movement also generating heat. Heat, in turn, affects subcutaneous fatty tissue, favoring lymphatic drainage, circulation within the affected area, the formation of new collagen as well as the migration of fibroblasts (Picture 9) [20].

\section{Methodological Approach}

\subsection{Therapeutic Acupunctural Resonance}

After my presentation at Beijing - and once Mariano Giacobone's dissertations on the relationships between structure and function in Occidental Medicine and Traditional Chinese Medicine were known [1]—our research focused on assessing how Nature adapts the forms created to the purposes of their consecutive functions. By extrapolating concepts from TCM to biological structures, we can call the parenchyma, Yang, as "corporatization" of energy; while Yin makes reference to stroma, the structure responsible for "nurturing" matter. Likewise, we can acknowledge the different states of matter and energy, making evident the distinction between the opposite polarities.

If we transfer such concepts to human biology, as regards structure, Yin or Stroma is the one containing the support tissue; whereas, Yang or Parenchyma represents the functional organic tissue of living systems [1].

As regards this analysis of "structure function", it was André Thomas-an eminent neurologist of La Salpetriére-who first coined the concept of muscular tone, describing the disorders that derive from disturbing it his new research field within Neurology [21] [22].

Likewise, and regarding "structure and its function”, Richard B. Fuller defined in his book Synergetics: Explorations in the Geometry of Thinking (1975) the notion of Tensegrity as the property "...some structures of isolated components have which are related through a tensional continuous network.” [23]. However, it was Kenneth Snelson who adapted this concept to that of Integrated Tension in biological systems, thus redefining them as "those systems capable of absorbing compression and distension in order to resume their original structural pattern” (Picture 10) [24].

In this way it was possible to interpret the notion of Integrated Tension in the structural balance of biological models, where the connective tissue components "interconnect" the whole body through coalescence fascias and the intersticial matrix: another fundamental "collagen wiring," arranged as a body "computing web" [2]. Then, tensegritical systems make an indirect reference to membranes—at architectural biological tissue level—as "connective structures capable of providing support and resistance to torsion, compression, traction, and flexion" (Figure 10) [24].
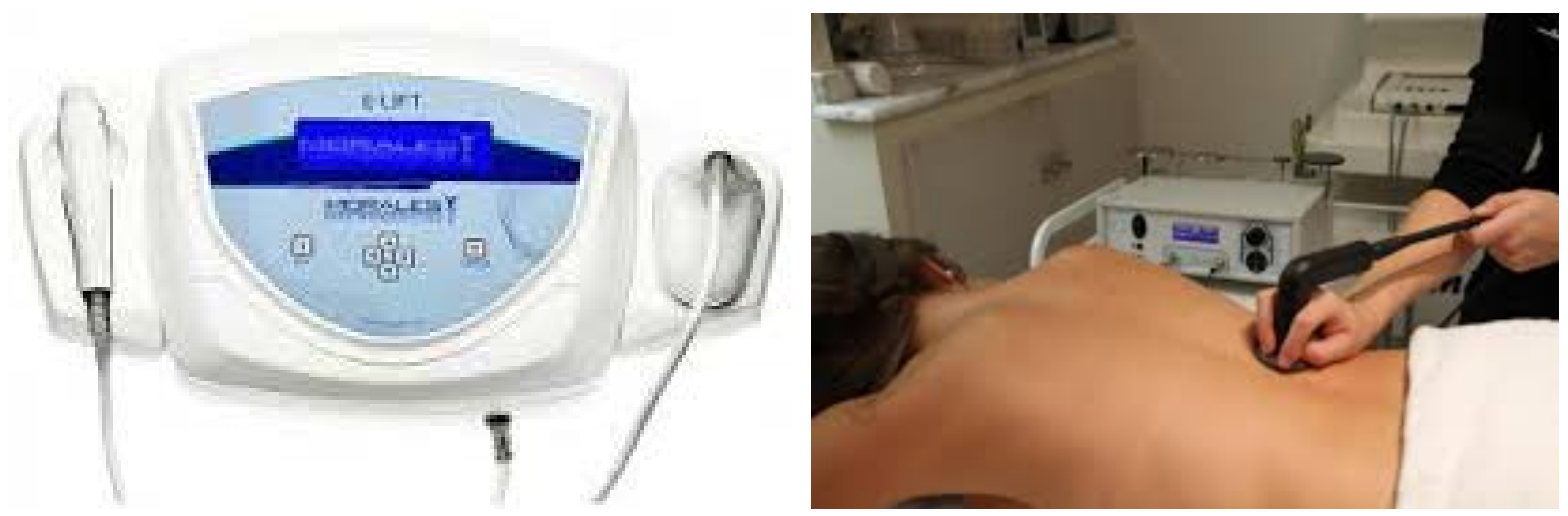

Picture 9. Radiofrequency treatment. Source: Radiofrecuencia: www.esteticasincirugia.es [20]. 
Thus, the notion of membrane as fascial network enables us to adapt the concept of muscular tone from Thomas to that of cellular tone, which in turn permits the introduction to the definition of Mechanical Transduction as a "property derived from kinetics that cells possess when bearing constant tensions on the filament of their cytoskeleton" (Figure 11) [1] [2].

Such knowledge-which can be made evident in physiopathology and therapeutics through the Tendino-muscular channels-shows the property the parenchyma has of "encoding" within its cellular DNA the heightened or diminished vibrations transmitted from the stroma nets as a "sensation of arrival and propagation of energy" (T'chi phenomenon) [1] [2].

This situation, known as Kinematic Cellular Indetermination (Figure 12) is also a concept which derives from kinetics and allows for interpretation of the role of (sound) stimuli which-through the connective fascia-reach and influence the expression of nuclear genoma.

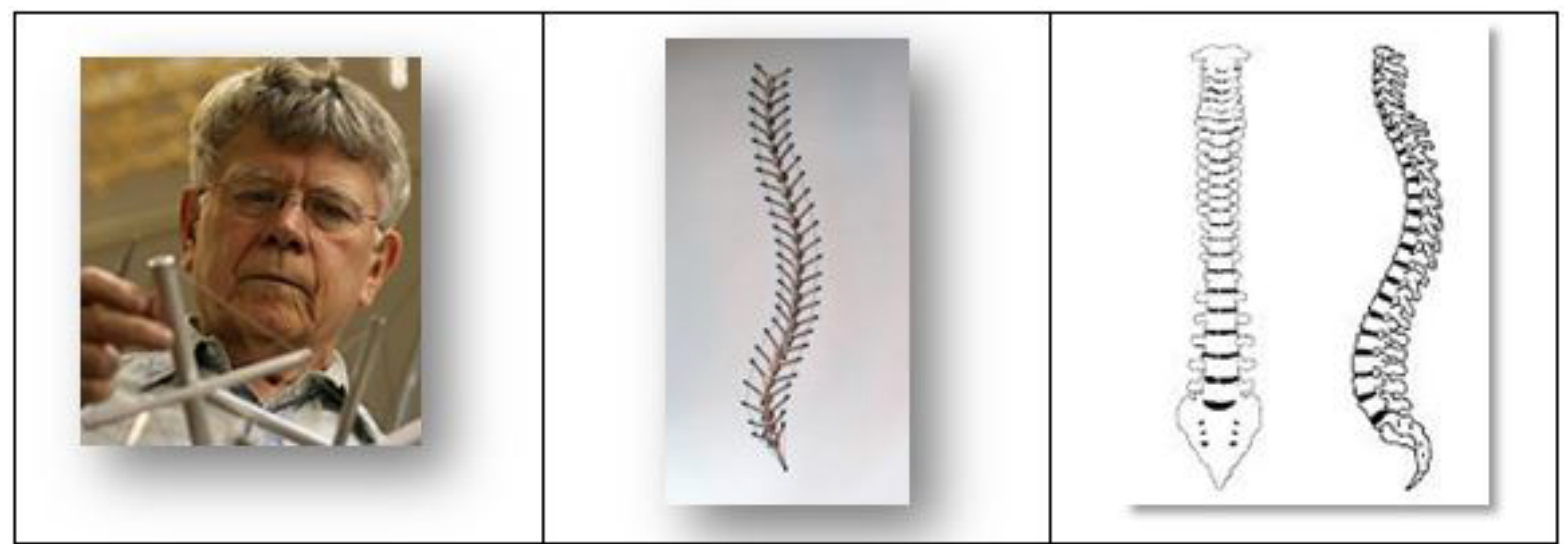

Picture 10. Comparison between tensegrity structures. Source: Gómez Jáuregui, V. “Tensegridad: Estructuras de Compresión Flotante”. Cap. 1 “¿Qué es la Ten-segridad?”; pp. 1-2.

http://www.tensegridad.es/Publications/Tensegridad-Estructuras_De_Compresi\%C3\%B3n_Flotante_by_GOMEZ-JAUREG UI.pdf [24].
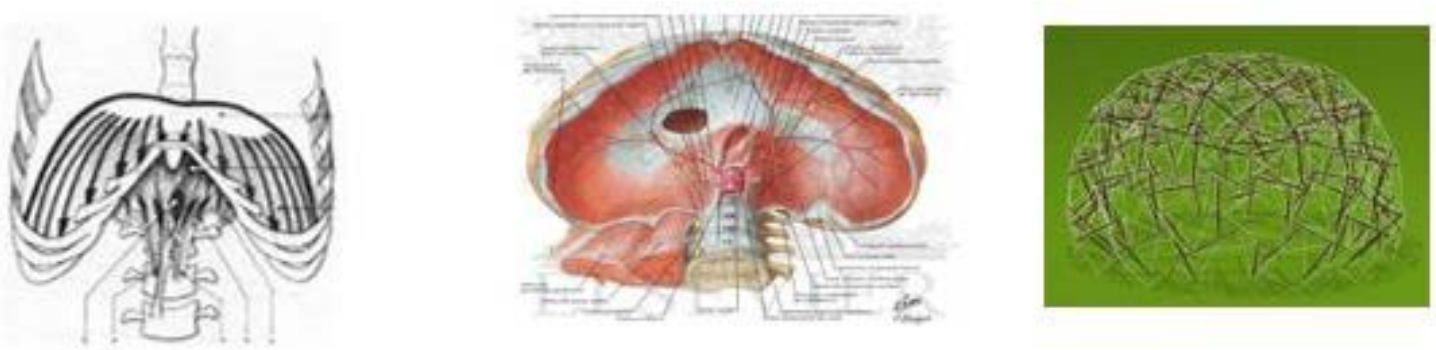

Figure 10. Biological tensegritic systems. Inchauspe, A. "Is Traditional Chinese Medicine definitely an exact science? Comparison between the oriental five elements' theory and Euclid five regular polyhedrons postulates” presented at the $2^{\text {nd }}$ International conference and exhibition on traditional \& alternative medicines. 2014. Beijing, China.

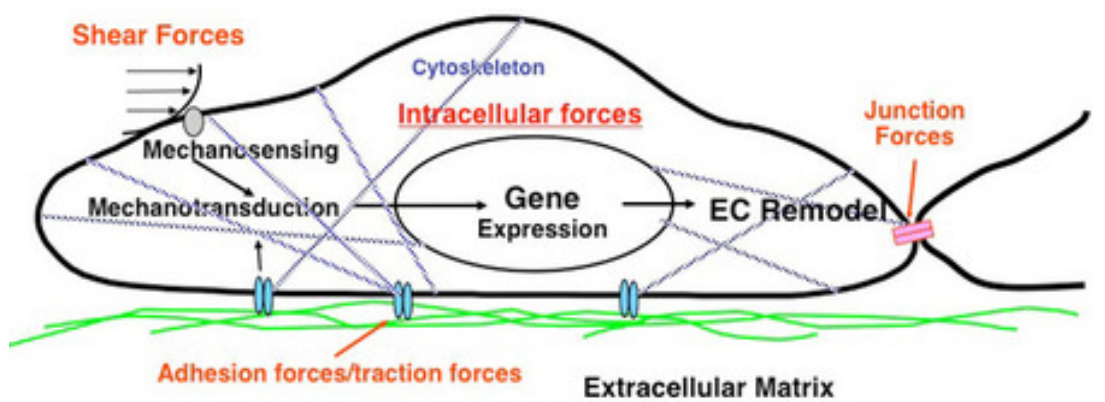

Figure 11. Use of DNA microarray technology to study gene expression. Source: http://chienlab.ucsd.edu/about. 


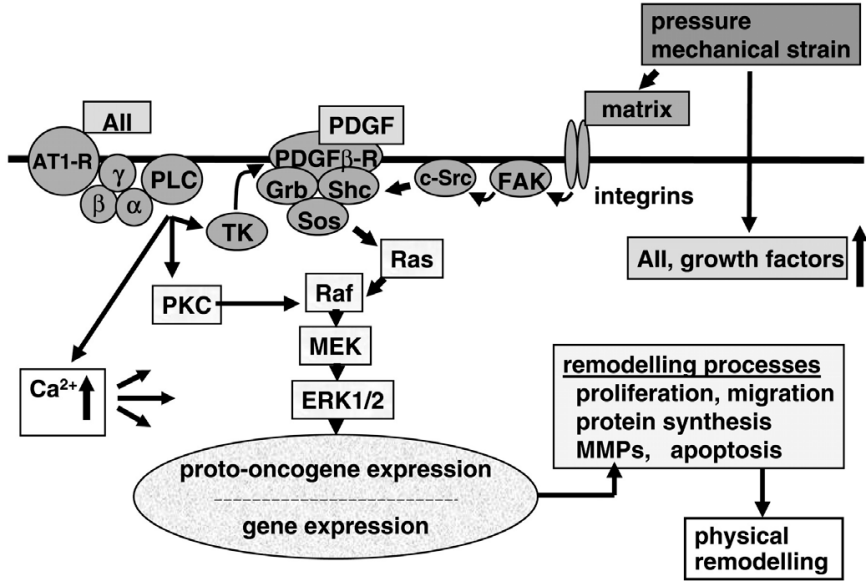

Figure 12. Kinematic Cellular Indetermination. Source: Mulvany MJ. Small artery remodeling in hypertension. Curr Hypertens Rep 4: 49-55, 2000.

From what has been described above, this tensional dimensional integration enables Nature's complex bio-structural systems to "integrate" each of its components in order to remain stable and-as epitome for its adaptation capacity-recover its original structural conformation.

All of this shall guide us through-as was stated in I-Ching as the Law of Energy Transformation of Lomonósov-Lavoisier-to an understanding of the changes produced at physiological as well as at structural level which occur within a biological system (the cell being the best example of this) and the way in which there can be adaptation in order to maintain an adequate internal dynamic balance [2] [25].

From the morphic resonsance point of view, such morphogenetic changes constitute an example of the intrinsic dynamic balance between biological coded information within cells and the resulting Geometry in the structure and development of organisms (Picture 11) [1] [24].

By way of conclusion for this section, let us share a phrase from Rupert eldrake: "Morphogenetic structures add the concepts from Ancient Oriental Wisdom and Sacred Geometry as mathematical support for its own reality" [2].

\subsection{Using Morphogenetic Fields in Acupuncture}

\section{Morphogenetic Fields}

This theory deals with the origin of forms and the behavior of natural systems which ar self-organized by the integrated influence of their morphic fields.

Such complex biostructural systems in Nature integrate the whole with each of their components so as to keep their stability [26]. The analysis needed in order to determine the number of necessary links a determined structure has to resort to so as to remain stable is called Kinematic Indetermination. This knowledge aims at clearing up the doubts that structural mechanics displacement presupposes.

Likewise, morphogenetic fields (Boveri, 1910) [26] also refer in human beings to an area in the embryo which affects the development of certain organs. Also known as embryological induction, a particular cell group which shall give origin to a determined biological structure, even if transplanted to a different part of the embryo (Gilbert, 1949). This concept is often compared to that of tissue ectopia [26].

The general aim of a morphogenetic field is determined by what the particular cell group shall render even if transplanted to another part of the embryo; thus, the behavior in the development of a cell shall depend on the instructional signals from its surrounding space: they presuppose the modular nature of embryo cells because of their relationship genotype/phenotype [26].

According to Gilbert, it is the morphogenetic field-and not genes or cells, what functions as the largest ontogenetic unit, the variations of which generate the changes in biological evolution (Gilbert, 1996). Such fields describe the intrinsic relationship existing between the biological information encoded in cells and the realization of the geometric form in the development of any organism (Morozova, 2013). Following Rupert Sheldrake, both concepts converge in the modern view of morphic resonance [2]. 

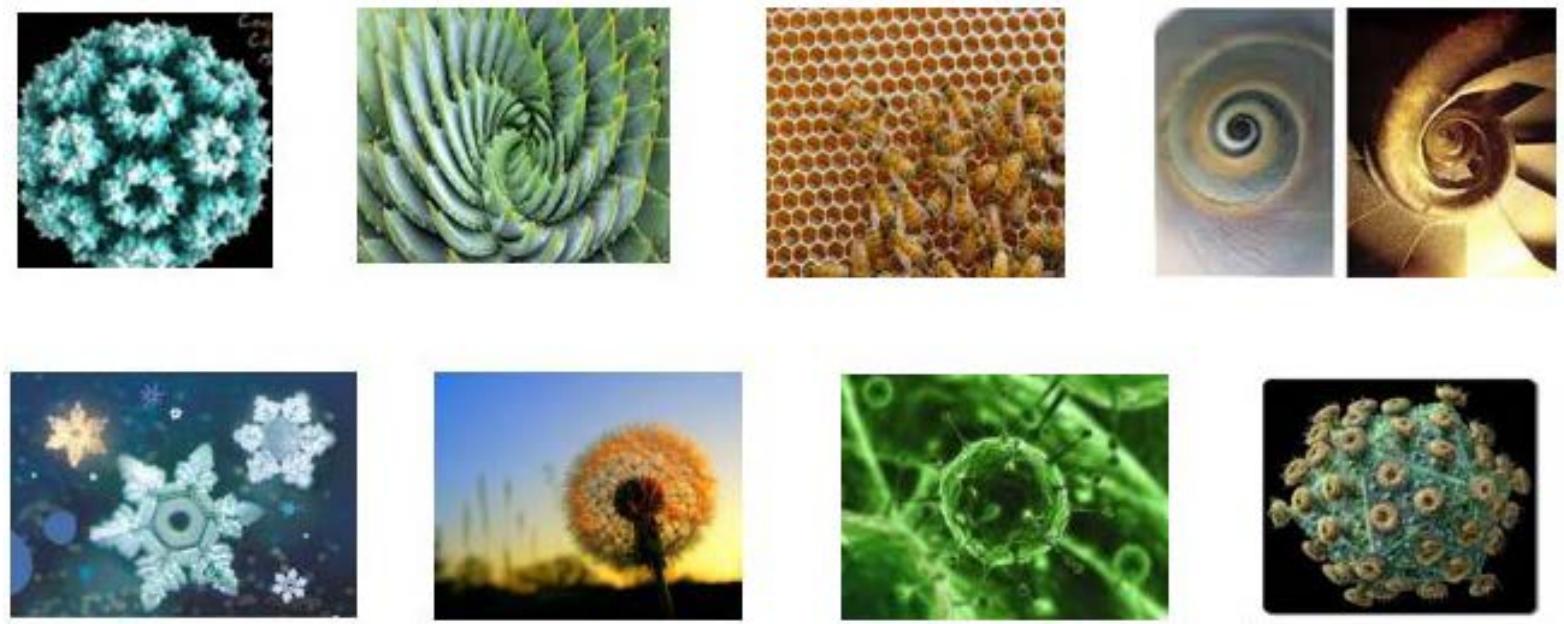

Picture 11. Geometric biological forms within morphic fields [1].

As regards morphic resonance, after having analyzed Euclid's propositions and the knowledge derived from them, such as Multidimensional Vectorial Geometry and those relating to biological structures, tensional dimensional integration, we find a current direct application linking morphogenetic fields theory and Chinese Acupuncture [2].

Together with the taxonomic designation proposed by Chinese medicine as regards the Five Main Elements (as Euclid had stated his Five Regular Polyhedra), the determination of corresponding musical notes-i.e. the vibrating frequency related to each of them-enables us to reestablish their vibration dynamics thanks to the restructure of their energetic frequency pattern along the meridian in question (Table 2) [2], thus:

Ever since Zou Yen (350-270 BC.) established the Theory of the Five Movements together with Yin/Yangas an action paradigm in Chinese Medicine, there appears minutely described, a grouping - activing very much as a general classification theorem [2] —over the various cosmic, seasonal, environmental, sensitive, emotional, organoleptic, etc. characteristics upon which the use of that information as support for action on that theory is grounded.

Consequently, as regards the sounds attributed to each of the Elements, the musical notes corresponding to each of the Five Movements are [3]:

- Wood: Do.

- Fire:La.

- Earth: Mi

- Metal: Re.

- Water: Sol.

It is worth remembering that Chinese music is pentatonic, a situation that most surely derives from its origin and integrated location within the Five Elements, which Pythagoras determines by means of his harmonic means and the Circle of fifths in order to exert their influence and harmonization on the meridians representing those Movements.

A simple way to check the incorporation of the ideal frequency rhythm for each cannel or to correct their unbalanced situation—following its Chinese syndromic diagnosis—is to insert through the needles, by way of "antennae" capturing said frequencies, which treat the condition, the restructuring frequency for the meridian affected and through it, of the element it belongs to.

Morphic Resonance therefore finds effective application when pins are used as "resonators" which put the frequency of the element of the channel in line, so that they transmit by means of punctures pure vibratory patterns which shall recondition the Qi flow frequency which has been altered by the Chinese syndrome diagnosed to be treated.

The way to access such harmonizing frequency might be established in different ways, for example:

- Use the Cheng or Generative Cycle sequence, starting from Wood in cases of organs (Yin) or from Metal in case of viscerae (Yang). 
Table 2. Energetic frequency patterns in the main meridians [2].

\begin{tabular}{cc}
\hline -Lung: $824 \mathrm{~Hz}$ (Reininger) & -Small intestine: $791 \mathrm{~Hz}$ \\
-Large intestine: $553 \mathrm{~Hz}$. & -Urinary Bladder: $667 \mathrm{~Hz}$ \\
-Stomach: $471 \mathrm{~Hz}$. & -Kidney: $611 \mathrm{~Hz}$ \\
-Spleen-Pancreas: $702 \mathrm{~Hz}$ & -Sanjiao: $732 \mathrm{~Hz}$ \\
-Heart: $492 \mathrm{~Hz}$. & -Gallbladder: $583 \mathrm{~Hz}$ \\
-Liver: $442 \mathrm{~Hz}$ & -Du y RenMai: $493,88 \mathrm{~Hz}$. \\
\hline
\end{tabular}

(An example for organ tonification: Do-La-Mi-Re-Sol)

(An example for visceraetonification: Re-Sol-Do-La-Mi)

Any of these sequences can be started by stimulating each note repeatedly till its influence on the channel is assured (6 - 8 times, approximately, at 4 - 6 second intervals in between each resonance)

- Use the manual pin turn tonification clockwise in case of tonification; and anticlockwise in cases needingdispersal.

- Another way of stimulating is considering the Mother-son rule of the Five Elements, i.e. using for tonification the sound of the previous Element to that affected in the Generative Cycle, and in cases of sedation, the following one within the sequence of that cycle.

- Stimulation by election of the musical sound which is suitable to the constitutional biotype of the patient or according to any of the TCM's principles.

- Stimulation according to the pairing of meridians which establish the Six Energetic Levels conforming TCM, that is:

Tai Yang Tai Yin

Shao Yang Jue Yin

Yang Ming Shao Yin

Lastly, one of the most efficient stimulations is the consecutive sequence of Therapeutic Acupunctural Resonance and, through the Chen or Generative Cycle sequence notes played in an almost uninterrupted succession (Do-La-Mi-Re-Sol) at intervals no longer than 4 - 6 seconds in between each note. This idea is supported in the five ancient Shu command points present in all the main meridians in Acupuncture, which presupposes-from TCM's perspective- the inclusion of the Five Element Theory in all meridians, thus enabling their regulation and energetic "tuning" by means of adding their sequenced resonances.

All the aforementioned is an already solved issue from the Exact Sciences. In the following scheme we can appreciate how Prof. Pedro González Urbaneja has managed to draw every inter-transformation of the Elements within the same polyhedron (Figure 13) [8].

In keeping with the demonstration or Euclid's regular polyhedral and the Elements of TCM, here we can see the mathematical support justifying the five elements and their sequential changes at each of the main meridians that make up our bioenergetic acupunctural map [25].

\section{Results}

The basics of tissue reconstruction of Therapeutic Acupunctural Resonance, supported by Mechanical Transduction, Kinematic Indetermination and Dimensional Tensional Integration which justify cell restructure and remodeling through the action of the resonance phenomenon throughout the cell's cytoskeleton (see the diagram in Euclid's work section above-Figure 11 and Figure 12)

The reverberation produced by the musical note chosen would recompose the vibrational patter, coupling and modifying the abnormal frequency of the meridian, liberating the normal flow of energy through it. In the course of this neurosensitive transportation several patients experience an enhanced pain threshold as well as an increased pain resistance threshold, very much like when PS is experienced [27].

It may be worth noticing, as regards what was stated above, that certain phenomena take place, e.g. T'chi (i.e. "energy arrival") and that of a "strengthened" propagated sensation or neurosensitive transportation referred to by patients who are treated with Therapeutic Acupunctural Resonance themselves. Unlike the first one which 


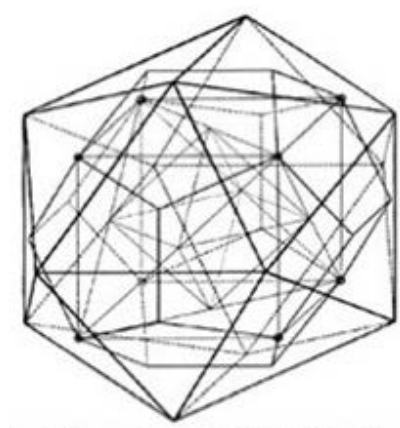

Figure 13. Inter-transformation among five regular polyhedral. Source: González Urbaneja, P. M. "Euclid's Elements-Mathematics’s Bible”; “The Propositions” [Translated title] pgonzale@pie.xtec.es [8].

means: to experience a certain numbness, pain, distension, languor or heaviness [28], neurosensitive transportation shares with SP the characteristic feeling of "something that is running". Such "tickling" sensation couldfollowing Edward LimChai-his — be attributed to the activation of neural fibers [29], more particularly, those of a peptidergic type [30].

Very much as the T' $T^{\prime}$ hi phenomenon is associated to pain, distension and heaviness after puncture (probably carried by type III or IV neural fibers), such neurosensitive transportation, which derives from the sound stimulation of the sounds corresponding to the Five Elements, appears in patients after the phenomenon mentioned above-like SP-without distinction of age, sex, race or occupation [28] in a painless way, and it is highlighted by patients when the line involving the meridians involved continues to be drawn, or is deviated from the original channel in order to reach the area affected [31].

According to TCM principles, the continuous flow of Qi through the main Acupuncture channels ensures good health in patients.

It is believed that $S P$ sensation recognition could be located at Brodmann areas 3, 1 and 2. Identical deductions are made for neurosensitive transportation, even though it may also manifest in dissociated from cortical activity [31].

According to Bossy, “...conscious sensation is cortical; however, the organization of such sensation is to be found at the primary centers of the neural axis" [32]. According to the embryological agreement between the skin and the Central Nervous System (let us remember the neural tube is generated from ectoderm during the third week of pregnancy) when the impulse runs through medullar areas corresponding to dermic stimuli [33]. As Lópezcompares in his magnificent book: "at the medulla area (plates II and III) there exists what can be considered a 'controlpanel' which informs us on the movement of a 'train' of neural impulses generated at skin level” [34].

The feeling of relaxation and a tendency to sleep-natural consequences after an acupunctural treatment-were more deeply manifested and for a longer period. In those cases in which patients evoke flavors, aromas or any of the categories listed in taxonomies of the Five Elements [2], it is worth to carefully confront them with their medical records so that a link between the reason for consultation and the actual disease of the nosological entities each patient presents may be established.

By way of conclusion for this section, let me share what Edgardo Lópezstated about propagated sensation: "Definitively, in order for this sensation to be made manifest, it requires a chain of impulses in an inter-neural structure together with a projection phenomenon from the upper structures. This sensation makes good communication between central levels and the periphery manifest. When it emerges clinically, we may rest assured of good initial acupunctural effects.” [35].

\section{Discussion}

A new phenomenon called neurosensitive transportation is equivalent to that one known as "propagated sensation" (PS) and the "ghost limb" sensation after amputation occurred [36]; but I would like to differentiate them from that achieved by stimulation of the pin's sound vibrations used for this technique.

Very much like PS, it does not exactly follow the somatosensory distribution of the neural territories where it 
is applied. It circulates slowly and bilaterally and does not restrict itself to one or more dermatomes [33] [36].

Unlike PS effect, neurosensitive transportation does not seem to slow down at the level of main articulations, neither because of cold nor because of pressure [30] [36].

Following the results obtained, the influence exerted by neurosensitive transportation may-like PS-reach the viscera or organ targeted for its application, thereby producing significant changes which favor the functionality of these structures when sensation reaches them [30] [37].

Now let us assess some of the formal counter indications of the therapies referred to at the beginning of this work:

Counter indications as regards acupunctural lasertherapy also list a series of situations to bear in mind:

- Retinaldamage

- Neoplastic processes (biostimulating ones and accelerators of cellular mitosis)

- Bacterial foci (acceleration and extension of the problem)

- Metal prosthesis_IUD—pacemaker (increased heat)

- Photosensitiveepilepsy

- Pro-photosensitive medicines (steroids-antimalarials-quinacrine-tetracyclines)

- Pregnancy[38].

As regards other therapies already mentioned such as ultrasound and radiofrequency, [39] it is known, for example, that the frequency used by those devices ranges between 1 to 3 megahertz $(1,000,000-3,000,000 \mathrm{~Hz})$. Such high frequency ultrasound radiation values may provoke blood cell stagnation in parallel with the ultrasound beam. Parasitical Head Radiations over $100 \mathrm{~mW} / \mathrm{cm}^{2}$ may even cause symptoms in those providing treatment (International Electrotechnical Committee-IEC).

Both for ultrasound as for radiofrequency there are, however, formal counter indications for therapeutic application:

- Severe heart disorders

- Coagulationdisorders

- Connective and neuro-muscular tissue diseases

- Collagenimplants

- Cancer

- Pacemakers and metal prothesis

- Pregnancy andlactation [19].

As regards Therapeutic Acupunctural Resonance, this simple practice:

- Does not presuppose any complication whatsoever beyond that of needle insertion (except for specific cases such as multifocal epilepsy).

- It "resets" the energetic flow in order to "unclog" obstructions and ensure the continuous flow through the channels selected for the therapeutics in question by a subjective amplification of the classical propagated sensation or neurosensitive transportation.

- It provides an enhanced emotional and general wellbeing, which is referred to by patients treated [40].

- Its practice has no counter indications as the conditions mentioned above and does not produce any secondary effects. The addition of this concept to classical acupuncture does in no way affect diagnosis nor the selection of points to be used, it does not delay the estimated time allotted to a patient for treatment.

Besides, it has the advantage of not muffling down sound vibrations-a situation that most often occurs when using the tuning fork directly on the points-which perpetuates stimuli on the needles (which receive sound waves like an antenna transmitting the frequency directly to the meridian in question)

In this therapeutic variation of Acupuncture, the patient has a more active role both because he is conscious and reveals new sensations to correlate with his clinical condition and because it offers a most useful sensitive feedback as reference of the therapeutic effect. This neurosensitive transportation effect (this denomination is used to separate it from the "pure" propagated sensation which results from classical Acupuncture) may be identified in cases of low tolerance to anxiety, where it has proved a most effective relaxation which seems to separate-however temporarily—-their Space-Time problem [41].

\section{Conclusions}

Ultrasound and radiofrequency therapies have become ever more relevant since the 1990s for post-surgical or 
post-traumatic rehabilitation treatments; that fact makes the therapeutic action of specific vibratory frequencies evident to achieve those results.

There have been other suggestions of vibratory therapies inspired in Acupuncture (such as that of Maman, in France) [17] and the bio-impedance of the meridians preceding this technique, though they were developed from different scientific hypotheses.

Therapeutic Acupunctural Resonance finds its foundations in the classical principles of TCM, and in no way does it subvert any of its therapeutic principles; this is done with a view to promote the effect of punctures in order to achieve faster and more effective recoveries.

Thanks to that knowledge the Chinese might have objectified the trajectory of the classical meridians and understand the expression of more complex physiopathological reactions the body has projected onto the skin surface, notwithstanding their lack of knowledge about the fundamental role played by the Central Nervous System. Nowadays, the analgesic and regulatory effects resulting from PS achieved by means of the Acupunctural therapeutics are widely accepted [41].

Following the concordance of the Classification Fundamental Theorem, both what Euclid stated in his propositions for regular polyhedra and the principles in TCM and its Five Elements clearly show-from a theoretical point of view - that there is scientific ground to access the therapeutic manifestation of the Morphic Resonance phenomenon during Acupuncture sessions, as was presented last year during the World Congress of Complementary and Alternative Medicines and before the authorities of the National Medical Science Chinese Academy at Beijing.

Likewise, Pythagoras' proposal paved the way for the development of Music and it is thanks to his arithmetic demonstration of the harmonic means and the Circle of Fifths we were able to find scientific-mathematical support to the development of Chinese pentatonic music involving the Theory of the Five Elements that regulates their TCM. This theory was introduced in the 3rd International Traditional Medicine 2015 Conference-Birmingham. United Kingdom from August 03-05, 2015 [42].

In Sheldrake's words, both Ancient Oriental Wisdom and Sacred Geometry-on flowing into Morphic Resonance-become "causative agents in the development and maintenance of biological forms". To some extent, both kinds of knowledge are compatible for the concordance of the internal dynamic balance that encourage and keep the vital processes.

\section{References}

[1] Giacobone, M. (2009) Morphic Resonance: A New Approach from Biology. [Translated Title]. (In Spanish). http://budacuantico.blogspot.com.ar/2009/12/la-resonancia-morfica-un-nuevo-enfoque.html

[2] Inchauspe, A. (2014) Is Traditional Chinese Medicine Definitely an Exact Science? Comparison between the Oriental Five Elements' Theory and Euclid Five Regular Polyhedrons postulates. Presented at the 2nd International Conference and Exhibition on Traditional \& Alternative Medicines, 25-26 August 2014, Beijing. http://dx.doi.org/10.4172/2327-5162.s1.006

[3] Jovenich, E. (2005) Theory of Five Movements. [Translated Title]. Monograph of the Educational Department of the Argentinian Society of Acupuncture, Buenos Aires. (In Spanish).

[4] Coop. Group of Investigation of PSC Beijing (1979) A Survey of Occurrence of the Phenomenon of Propagated Sensation along Channels in the Mass and Its Basic Properties. Adv.in acup. and acup-an.

[5] Euclides (2000) Elements. Book I-IV: General Introduction: The Constitution of the Elements. 1. Gantry Axiomatic, 48-65. [Translated Title]. Classic Gredos’s Library, Madrid. (In Spanish).

[6] Euclides (1996) Elements. Books I-XIII. [Translated Title]. Classic Gredos’s Library, Madrid. (In Spanish).

[7] Euclides (2000) Elements. Book XIII: Proposition 18, 355-56. [Translated Title]. Classic Gredos’s Library, Madrid. (In Spanish).

[8] González Urbaneja, P.M. “Euclid’s Elements—Mathematics’s Bible”; “The Propositions” [Translated Title]. (In Spanish).

[9] González Urbaneja, P.M. “Critical Study of Three Works Summit of the Mathematics Literature”. Volume I: “Euclid’s Elements”, 168: “The Philosophical Substrate of Euclid’s Elements”. [Translated Title]. (In Spanish).

[10] Dunham, W. (1996) Travel through the Geniuses. 116. [Translated Title] Editorial Pyramid. Madrid. (In Spanish).

[11] Cooper, J.M. and Hutchinson, D.S., Eds. (1997) Plato: Complete Works. “Timaeus” (Or “Timaeus’ Exposure”). Introduction: "Constitution of the Elements.” (Translated Title). 52nd Patricio de Azcarate Edition, Volume 6, Madrid. (In 
Spanish)

[12] Cecilia Tomasini. http://latindecuisine.blogspot.com.ar/2010/01/las-artes-liberales-el-trivium-y-el.html

[13] Wikipedia. http://sauce.pntic.mec.es/ rmarti9/WebBabilonia/Biografias/Pitagoras.htm

[14] Cobos Romana, R. (2013) Acupuncture, Electroacupuncture, Moxibustion and Related Techniques in the Treatment of Pain. Revista de la Sociedad Española del Dolor, 20, 263-277. (In Spanish)

[15] Laser Therapy: Innovative Treatments and Ailments. (In Spanish) www.lasersalud.es

[16] Chia, M.M. (1995) Fusion of the Five Elements-Basic and Advanced Meditations to Transform Negative Emotions. Formula Four: Transforming Negative Emotions of the Bodies into Usable Energy. (Translated Title). Ed. Sirio, S.A. Málaga, 91. (In Spanish)

[17] Tama-Do. http://tama-do.com/product/tuningforks.html

[18] Topology System. http://trade.nosis.com/es/www.acupunturaorekavitoria.com/1311065/s

[19] Ultrasound Therapy. (Translated Title) (In Spanish) http://www.astook.com/ultrasonido-para-adelgazar-o-cavitacion-ultrasonica-pros-y-contras/

[20] Radiofrequency. (Translated Title) (In Spanish) www.esteticasincirugia.es

[21] Alix, G. "Muscle Tone and Strength”. “Generalities”; Neurologic Evaluation of the Newborn”. 569. (Translated Title) (In Spanish) http://se-neonatal.es/Portals/0/Publicaciones/EVALUACION_NEUROLOGICA_DEL_RECIEN_NACIDO[2].pdf

[22] Barraquer-Bordas, L. and Codina-Puiggros, A. Semiotics of Muscle Tone Disorders, 20. (In Spanish) http://www.bvsde.paho.org/texcom/revneuropsiquiatr/LBarraquer-Bordas.pdf

[23] Fuller, R.B. (1975) Synergetics: Explorations in the Geometry of Thinking. www.amazon.com/Synergetics-Explorations-Geometry-Buckminster-uller/dp/002541870K

[24] Gómez Jáuregui, V. Tensegrity: Structures of Floating Compression. Cap. 1 “What It Is Tensegrity?” 1-2. (In Spanish) http://www.tensegridad.es/Publications/Tensegridad-Estructuras_De_Compresi\%C3\%B3n_Flotante_by_GOMEZ-JAU REGUI.pdf

[25] Chamfrault, A. and Van Nghi, N. (1969) L Énergétique Humaine en Medecine Chinoise. Cap. I “Nociones Generales”. Imprimiérede la Carente, Angoulenne, 8.

[26] Morphogenetic Field (Developmental Biology) (In Spanish) https://es.wikipedia.org/wiki/Campo_morfogen\%C3\%A9tico_(biolog\%C3\%ADa_del_desarrollo)

[27] Meng, Z.W. (1979) The Origin, Establishment and Prospect of the Theory of Channels. Symposium of Acupuncture and Moxibustion and Acupuncture Anaesthesia. Beijing, June 1979.

[28] López, E. (2005) Chapter 2: Neurophysiology of Acupuncture-His Mind-Body Relationship. Ed. Serendipity, Buenos Aires, 51. (In Spanish)

[29] Pan, C.C., et al. (1991) A Research of Correlation on Neuropeptide and Electroacupuncture Effect. Acta Medica Sínica, 6, 6.

[30] Coop. Group of Investigation of PSC (1979) A Survey of Occurrence of the Phenomenon of Propagated Sensation along Channels in the Mass and Its Basic Properties. Adv. In acup, And Acup-an. Beijing, June 1979.

[31] The People's Hospital of Guangxi Zhuangzu Automous Region (1979) The Phenomenon of Propagated Sensation along Channel and the Cerebral Cortex. Department of Neurological Surgery, Adv. In acup and acup-an. Beijing, 1979.

[32] Bossy, J. (1973) Bases morphologiques et functionelles de l'analgesieacupunturale. Giornaledell Academia de Medicina de Torino, Torino.

[33] Bossy, J. (1995) Les dermalgiesreflexes. Acupuncture Course in Buenos Aires.

[34] López, E. (2005) Chapter 2: Neurophysiology of Acupuncture-His Mind-Body Relationship. Ed. Serendipity, Buenos Aires, 55. (In Spanish)

[35] López, E. (2005) Chapter 2: Neurophysiology of Acupuncture-His Mind-Body Relationship. Ed. Serendipity, Buenos Aires, 56. (In Spanish)

[36] Res. Group of Acup., Anesth. Instit. of Medic. and Pharm. of Fujian, China, 1979.

[37] López, E. (2005) Chapter 2: Neurophysiology of Acupuncture-His Mind-Body Relationship. Ed. Serendipity, Buenos Aires, 53. (In Spanish)

[38] Hernández Díaz, A. The Low-Power Laser in Current Medicine. (In Spanish) http://www.sld.cu/galerias/pdf/sitios/rehabilitacion-fis/(monografia._el_laser_de_baja_potencia_en_la_medicina_actua 205)_1.pdf 
[39] Radiofrecuency. (In Spanish) www.tesis.uchile.cl

[40] López, E. (2005) Chapter 2: Neurophysiology of Acupuncture-His Mind-Body Relationship. Ed. Serendipity, Buenos Aires, 54. (In Spanish)

[41] Res. Group of Acup. Anaesth. Instit.of. Medic and Pharm. of Fujian. (1979) The Electroencephalographic Observations on Subjects with Marked Propagated Sensations along Channels. Adv. in Acup. and Acup-on. Beijing, June 1979.

[42] Inchauspe, A. (2015) Therapeutic Acupunctural Resonance. Proceedings of the 3rd International Traditional Medicine 2015 Conference, Birmingham, 3-5 August 2015. 